\title{
Socio-Anthropological Problems of Education in the Consumer Society and Information Technologies
}

\author{
Olga L. Sytykh \\ Altai State University \\ Lyudmila K. Sintsova \\ Altai State Pedagogical University \\ Maxim B. Maximov \\ Altai State University
}

This paper aims to show the inconsistency of the process and results of informatization for people, culture, and society, where consumption becomes its characteristic feature. We note that with the wide spread of education in the modern world, which to a certain extent became possible due to the development of information technologies, its depth disappears, and it becomes less qualitative. The research is based on the dialectical method, and it allows us to identify both positive and negative aspects of the introduction of information technology in the educational process. The system and structural-functional methods proved to be useful for a comprehensive analysis of education in the context of social changes, establishing a number of relationships and transforming the cognitive abilities of a person as a subject of education. The research novelty lies in the identification of changes that occur in the subjects of the educational process under the influence of the introduction of information technologies. Such socio-anthropological changes became an important philosophical and scientific problem that requires further interdisciplinary research.

Keywords: society, consumer society, market relations, education, knowledge, information, information technology, professionalism, people, reflection, critical thinking

\section{INTRODUCTION}

The changes taking place in Russian society are complex, because they affect all aspects of life and every person living in Russia. Changes in Russian society are of multi-factor nature. They are due to general changes in the world, including (1) informatization, (2) globalization, (3) the transition from socialism to a market economy, (4) the formation of a consumer society, (5) the assimilation of liberal values, and (6) the rejection of the values of socialism. All these factors led to new benefits for human development. However, they also created additional difficulties in some aspects of people's life.

The peculiarity of modern Russian society is the changes that cover all aspects of people's life. Many of them bring great benefits to human life. Nonetheless, almost all human achievements have their downsides. 
Behind all obvious achievements that civilization generated and without which humanity can no longer imagine its existence, we see the contours of phenomena that pose a potential threat to humanity. For example, N. V. Motroshilova raises the problem of the revival and development of barbarism in modern society (Motroshilova, 2010). Besides, she notes:

Modern barbarism can be defined as a set of phenomena, forms, and lifestyles of people existing at the mature stages of development of civilization, which are strikingly different from the trends and essential principles of civilization. They are characterized by (1) brutal violence, (2) extreme cruelty, (3) catastrophically destructive historical consequences, (4) shameless violation of civilizational principles and norms well-known to humanity, unworthy of human savagery, bestiality, and other signs indicating a rollback to barbarism (Motroshilova, 2010, p. 81).

In the $21^{\text {st }}$ century, this phenomenon can be seen in (1) trafficking in human organs, instilling fear, violence, evidenced by the information on the internet and in the media. Now barbarism is also manifested in attempts to rewrite history. For example, the demolition of monuments to Soviet soldiers liberators, when these soldiers are declared conquerors. Playing with historical memory is always barbaric because it is destructive to consciousness. This game is also expressed in attempts to abandon the historical traditions and the rich cultural past of the peoples inhabiting Russia. Behind the cultural and historical traditions, there is a system of universal values, including the attitude to nature and society. Today, barbarism has many faces. It is not something external to civilization (as L. Morgan believed). Instead, the barbarism is generated by it, embedded in it. In the $21^{\text {st }}$ century, it is manifested in the slave trade, trafficking in human organs, the relishing of violence in life, in the media, and on the internet. Modern barbarism is the destruction of historical memory (the revision of the results of the World War II, the destruction of monuments designed to perpetuate the deeds of heroes), a break with historical traditions, the rejection of socio-cultural experience of humanity, including the relationship between people, the attitude to culture and society. What influences these destructive processes? What opens the possibility for their similar flow? We think that modern education plays an important role in these destructive processes and allows them to proceed. It is especially relevant for Russia, which changed over the past three decades. In the past, the education in Russia was accessible and equal for everyone. Later, Russia joined the Bologna process, which declaration proclaims the availability of education as the highest value of modern society. In the $20^{\text {th }}$ century, many people wrote and said that modern society was a society of knowledge. However, what is more surprising is the situation in which social science began to rapidly "produce the society of ignorant" (Grechko et al 2009, p. 206).

On the one hand, modern society is proclaimed a knowledge society focused on education. On the other hand, there are a lot of professionally incompetent people in our society. High-quality performance of labor functions is a rare phenomenon. It leads to dissatisfaction with education on the part of both employers and individuals, and a discussion in the media about the quality of education.

In the modern world, people are increasingly talking about functional illiteracy and professional incompetence. Functional illiteracy is defined as the inability to live in a modern society and the lack of good reading, writing, and numeracy skills. Today, digital illiteracy and the inability to master information technologies are also typical for functional illiteracy.

Many researchers note that the modern society focused on education is characterized by functional illiteracy, professional incompetence, and dissatisfaction with the quality of education, both on the part of the society and on the part of the individual.

A person must be able to learn while living in a constantly changing social world, in a market economy. People should be able to adapt. To achieve these goals, it is necessary to master numeracy, reading and writing skills, as well as the digital world. Oleg Podolsky, head of the Training Design and Competence Development Group at the Higher School of Economics, analyzed the results of the first Program for the International Assessment of Adult Competencies [PIAAC] study on key adult competencies (Podolsky, 2015). The event was attended by both countries of Organization for Economic Cooperation and Development [OECD] and partner countries, including Russia. This report highlights countries with low (e.g., the United States and the United Kingdom), high (e.g., Finland, Japan, and Belgium), and medium reading literacy (e.g., Russia). It also contains possible reasons for low reading literacy (first of all, the 
ability to read and understand the text). One of the reasons for this phenomenon is the inequality of educational opportunity. Therefore, functional illiteracy is dangerous for everyone, including developed countries. A functionally illiterate person does not know how to (1) analyze, (2) highlight the main things, (3) improve their skills, (4) retrain, (5) conduct a discussion (i.e., competently interact with people), (6) solve their problems with the help of knowledge. All these factors make people vulnerable and "unfree" in terms of determining the trajectory of life.

The manifestation of functional illiteracy can also be considered professional incompetence expressed in the limitations, imperfections, and inferiority of the specialist (Toshchenko, 2008, p. 432). Currently, many people face professional incompetence in various areas affecting their daily lives (from schools and clinics to training for senior management structures). Against the background of functional illiteracy and professional incompetence, which are characteristic of different countries and peoples, the world has entered the Information Age, which has covered all aspects of life and has a particularly intense impact on education.

The purpose of this paper is to show the contradictory nature of the process and results of informatization for people, culture, and society, in which consumption becomes its characteristic feature.

\section{MATERIALS AND METHODS}

The use of the dialectical approach in the analysis of Russian and foreign scientific and philosophical literature, as well as the reliance on specific social phenomena, allows us to identify some contradictory processes occurring in modern society. A comprehensive study of objects and phenomena prescribed by dialectics shows what difficulties people face today living in the Information Age. On the one hand, the widespread introduction of information technologies in various areas makes people's life more comfortable. On the other hand, people lose certain previous skills formed by centuries of communication tools characteristic of national culture. This is particularly evident in the field of education, where changes are analyzed on the basis of systemic and structural-functional methods. The system method, aimed at considering education as a single system interacting with other social systems, allows us to identify education as a factor of the construction of the society, which influences (1) its culture, (2) material and spiritual areas, (3) human values, and (4) goals of social development. The structural-functional approach allows to conduct an in-depth analysis of the connection and influence of consumer attitudes of young people with (1) their needs in education, (2) the use of information technologies in this field, and (3) the formation of competencies for future professional activities. The use of the methods mentioned above (philosophical, dialectical, general scientific, systemic, and structural-functional) allows us to form a picture of socio-anthropological changes occurring in modern society (consumption) under the influence of information technologies.

\section{RESULTS}

\section{What Should Education Be Like?}

The orientation of education to values (this is what many experts see as the vector of educational orientation) has two main aspects: material and spiritual. Material one is related to the orientation towards material values, which should determine education, professional life of a person, and the development of society. Spiritual aspect is related to the orientation of education towards spiritual values. Within the framework of the material aspect, there is an opinion that the main task of education is to meet the needs of business in personnel. Hence, many of the ideas are enshrined in the Bologna Declaration. In particular, they are aimed at creating personnel that are equally in demand and professionally suitable for work in different countries. This is important for solving the problem of the labor market. The spiritual aspect of education is associated with the priority of spiritual values, the highest of which is the self-realization of the individual. Therefore, education should help people to discover their abilities and potential, which in the future will determine their path, life goals, and objectives. These aspects are interrelated. Orientation in education to spiritual values does not contradict the orientation to material values, considered as part of the 
whole. Through education, people reveal their abilities, due to them, they acquire the opportunity for active self-realization in society. Therefore, the goal of education, defined by the German philosopher M. Heidegger, is achieved. According to his concept, "the word "form" means to set a pattern and set a prescripture. Its other meaning is to form the existing makings. Education shows a person pattern by which they organize their actions and inactions" (Heidegger 1993, p. 252).

The value of this approach lies in the priority of the formation of the individual as the basis on which the development of society and all its areas, including material and spiritual production, are based. The disclosure of the potential abilities of a person, their transformation into real skills and abilities makes it possible to form a personality according to the model (desired image), creatively push the boundaries of existance, in accordance with social world and national trends.

Thinking based on reflection is an important element of education. A person should measure and evaluate what they know, how they get knowledge, and how to make this process effective. G. P. Shchedrovitsky, a well-known expert in reflexive processes, considered reflection as an important way of organizing methodological thinking and activity, connecting "individual thinking and individual activity to the social, universal phenomena" (Shchedrovitsky, 1997).

The introduction of knowledge during the era preceding the information boom, encouraged people to think and reflect. The method of obtaining knowledge required students to work with a book, which included visiting libraries, which are now fairly empty.

Coming to the library, a school or university student who uses a systematic catalog (when a topic is given without reference to authors) decides in which section to look for the recommended literature. Even such a simple involves a systematization of the content material with which the person worked, based on the knowledge and ideas already available to them. This process also implies reflexive mechanisms that are important for introducing the world of culture and the experience of humanity, forming methods of working with knowledge and understanding the world of knowledge. The next stage of the work is to review, read papers and monographs, select, and, finally, take notes of the material necessary for understanding the given topic. Then, the person obtains a new systematization of the entire complex of knowledge. Each of these procedures opens up wide opportunities for creative thinking and the development of intelligence. Trained in this way, a person became a thinker. This process is an undeniable advantage of the old book training of a specialist with a higher education.

\section{Implemented Opportunities of Information Technologies in Education With Positive Results}

The huge advantages of new information technologies are (1) easy and fast access to information on the internet, (2) the availability of previously inaccessible libraries, and the ability to purchase for work and study the books that were recently ordered by the IBA and whose delivery to the reader lasted for several months. Currently, all subjects of the educational process have quick access to a large database of educational, scientific, and popular science literature (textbooks, monographs, papers, conference proceedings, etc.).

Test materials also bring some benefits. Using them, the teacher and the student can check the level of development of a particular subject. The preparation and competent planning by the teacher of work with tests of various levels, allows the student to gradually reach a higher level of mastering the material. Creating tests at a good methodological level requires the trainee (student) and supervisor (teacher) to develop a consistent and clear conceptual and terminological structure of the course. Such a structure implies that the concepts and theses in tests grouped by topics and sections of the curriculum of the discipline. Due to the mastery of the conceptual apparatus, it is easier for the student to assimilate the complex problems of the studied topics. This development, along with the program, is an independent methodological material for ensuring the quality of teaching.

Information resources allow one to quickly get acquainted with the latest news of politics, science, technology, and culture and include them in one's work (this is especially important when studying social and humanitarian disciplines). Getting acquainted with the opinions of leading politicians and cultural figures on various issues, as well as the development of current scientific projects and new technical 
achievements, expand the horizons of school and university students and allow them to consider the studied material in the context of modernity.

Under certain conditions, one can get access to lectures by professors from the best universities in the world and even conduct a dialogue with them. Some European and Russian universities already use this opportunity. There are platforms presenting a range of materials for free. Everyone can attend a large number of courses for free, both in various educational programs, and not related to any programs, but aimed at satisfying the cognitive interest in a particular area.

A certain system of inclusion of information resources in the educational process (their selection, sequence, etc.) allows one to implement both the declared educational programs and hidden ones aimed at ideological (humanistic, patriotic, etc.) education. The orientation of ideological training largely depends on the material and tasks that are offered to school and university students. The appropriate selection of this material for compulsory education makes it possible to emphasize the pacifist, patriotic, militaristic (unfortunately), gender, or any other component in education. Hence, with all respect for academic degrees and titles of well-known foreign scientists, it is necessary to remember the goals and objectives of teaching social and humanitarian disciplines in the country where the students live. Undoubtedly, knowledge of specific historical and political facts is necessary. It is well known that the content of the history textbook for the European Union has been discussed for a long time. Nevertheless, even today, it is not mandatory in Japan, America, China, and other countries that are not members of the Union.

Only a small part of the benefits of using information technology to expand educational opportunities are listed above.

\section{Some Negative Consequences of Using Information Technologies in the Educational Process in a Consumer Society}

Market relations in modern Russia extend to all areas of life, including education, as an important stage in training young people. That is why education is regarded as one of the elements of an extensive service sector. Information technologies introduced in education should perform the same task as the education system: prepare young people for life in the market.

The consumer society is interested in people whose minds can be manipulated. There is no need for deep and original thinking. The society focuses on material values and social success. The orientation of a person to strive for success at any cost, believing that this success will bring benefits in the form of material values, ultimately distracts from the cognitive function towards competition. "Knowledge is not the main thing," it is more important to be noticed and appreciated to advertise oneself. The chances to achieve this due to deep knowledge are low. The reliance in education on a number of instinctive motives forms a manipulative thinking. For example, the successful person presented in the ad in a certain outfit evokes a persistent desire: "I need it too." This is where the member of the consumer society appears "in all its glory." People have to decide whether they really need this thing., whether it suits them, or whether it just needs to be bought (in my head, "be successful").

School and university students use the materials presented on the internet when preparing for classes. This use goes the shortest way, with the least intellectual cost. In the "Search," they formulate a question, look, and download the material offered by the web. Such information often does not coincide with the authors studied in the classroom. It is not related to scholarship and far from serious scientific research. First of all, the student aims to prepare for the lesson without serious intellectual expenses. Simultaneously, reflexive mechanisms are not involved at all. The network makes choices for the student, and the parameters that guide them focus on saving thinking (the text should be small and easy to read; sometimes the teacher's wish is also taken into account, if it does not contradict the first two conditions).

In the classroom, the student often just reads the material found on the internet. Sometimes text printouts are used for this purpose. Quite often, students use gadgets (reading from computers, smartphones, etc.). Therefore, the current widespread use of materials presented in the internet by students do not form a critical attitude to the materials used, do not develop reflection. Such mastering of the material, without proper reflection on it, as a purely mechanical reproduction forms a person who is not able to critically 
perceive information, which means that they can be easily manipulated. Manipulation is a characteristic feature of the consumer society in which they live.

In the modern educational environment, there are various tactics and strategies of educational activities. Some students get acquainted with educational materials by studying preparing for classes (the best option). Others do not bother with this, printing out the material to work with it in class. Most often, they bring their own individual equipment (smartphones, laptops, etc.), using which they find these materials right in the classroom. In the absence of memory and thinking training, the work can eventually be reduced to reproducing texts in the classroom by simple and almost unintelligible reading. A person who learns this way is easily manipulated. They are the ready-made subject-object of consumer society. Their desire for success and material well-being, which they do not want to postpone for later (postponed understanding of the material), leads to the fact that the purpose of the education is to obtain a diploma; not the ultimate goal, but the only one. This position is clearly seen in the answers of undergraduates to the questions of the questionnaire offered to them. For example, answering the question, "What does education give a person?" undergraduates mostly referred to the phenomenon of diploma magic, typical for the public consciousness of modern Russian society. The diploma is associated with a permit or pass to a happy life:

"One cannot get a prestigious, high-paying job without diploma";

"It is worth spending time on higher education, to get the diploma for career growth";

"Diploma is the benefits of education, which will help one to get a good job";

"Without paper you are a bug, but with a paper you are human." (Russian proverb).

However, a significant number of respondents associate the goal of education with knowledge:

"Education is a purposeful process of gaining new knowledge and skills";

"Education is the acquisition of scientific knowledge";

"Education is a set of systematic skills and knowledge acquired in the educational process at institutions or self-education";

"Education is a form of obtaining of knowledge, abilities, and skills";

"Education is the knowledge that should be implemented in the modern world."

It seems that this approach to defining the essence of education reflects the personal experience of both school and university education of respondents. The knowledge or traditionalist paradigm of education prevailed in this process. Its main goal is to transmit to the younger generation the most essential elements of the cultural heritage of humanity accumulated over the centuries. This transfer is based on the acquisition by students a set of knowledge, skills, and abilities that have stood the test of time and became classical. This approach is likely to be replicated by respondents in their future professional activities.

It seems that the connection of education with knowledge among the students, is not accidental. Throughout the years of study, they were evaluated according to the amount of knowledge acquired. It is surprising that today's young people who live on the internet do not associate rapid technological development with (1) changes in the socio-economic sector of society, (2) variability of labor market demands, (3) new requirements of society for the education system. Knowledge is rapidly becoming obsolete today. According to A. M. Pyatigorsky, "In addition to all specific and functional knowledge, education should serve as the main resource for independent personality, where intellectual independence 
is the most important" (Pyatitgorsky, 2018). Today, the result of our educational activities is not only knowledge, but also the ability to think, critically perceive, and analyze information.

This educational strategy, which consists in the formation and development of students' critical thinking, is reflected in the works of P. McLaren, A. Giroux, M. Green, P. Freire, and other scholars. According to representatives of critical pedagogy, "Narrative learning leads to the fact that students mechanically remember what is said. Worse, it turns them into storage containers that teachers fill. The more they fill this container, the better teachers they are. The more meekly containers allow themselves to be filled, the better students they are" (Freyer, 1970).

In contrast to the encyclopedia, representatives of critical pedagogy believe that the task of education is to develop critical thinking among students, which contributes to (1) the vision and understanding of the world in its contradictions and variability, (2) identifying the source of existing conflicts, (3) being aware of the relationship between the part and the whole, the process and result, subject and object, being and becoming, structure and functions. To form the critical thinking of students means to form the scale of their thinking, the ability to see the whole phenomenon entirely in its contradictions and development. Critical thinking skills allow one to see not only individual objects and phenomena, but to find the general and universal behind them, to analyze not individual events and facts, but to see the causes of these events. Critical thinking is a system of judgments used to analyze things and events with the formulation of reasonable conclusions. It allows one to make informed assessments, interpretations and correctly apply the results to situations and problems (Facione, 2016; Freier, 1972). Due to critical thinking, a person can not only find the necessary information but also critically perceive it: evaluate, compare, analyze, compare, and interpret.

There are several negative effects of verifying the knowledge of students by tests. In the previous section, we noted the positive aspects of their use. However, there are also negative consequences of their widespread use, especially in terms of attempts to make them the only way to test knowledge. It is impossible to disagree with the fact that, "The tyranny of texts and tests leads to the fact that people live in a vague state of dissatisfaction with themselves, feeling like unnecessary garbage thrown to the curb by a powerful information flow" (Mikhailova, 2009).

The formalization of humanitarian knowledge to questions and clear answers to them, from several possible options, is a major and difficult problem for the humanities. The difficulty lies in the fact that the most profound works of literature and the most significant historical events must be assimilated not only at the level of knowledge, but also at the level of understanding. Checking the understanding of the material by testing seems to be unproductive (more precisely, ineffective). Creative students, who usually easily demonstrate their knowledge in a conversation with a teacher and in a group, are lost when answering test tasks in the humanities. It is necessary to choose an answer, and none of the proposed options does not coincide with their understanding of the material. This leads to the conclusion that well-prepared and deepthinking reflective students are most vulnerable as a result of tests. Special attention should be paid to the fact that today, education in high school has turned into preparation for the Unified State Exam [USE], and the latter is reduced to a simple training. High school students are deprived of the opportunity to fully study subjects, both specialized (those that they plan to take on the USE) and non-core (which they consider unnecessary).

Today, the consumption of necessary information, due to its development, the formation of a scientific worldview, and a holistic picture of the world is observed by teachers working at all levels of the educational process and often emphasizing the fragmentary consciousness of modern youth. Both methodically and conceptually, the raw use of information technology reinforces this trend.

\section{DISCUSSION}

The rapid change in the social world entails a change in the life of every person. New information technologies, new means of communication, opportunities for virtual visits to shops and art galleries, the best museums in the world, and the best universities, new methods of learning and obtaining information provide new opportunities for human improvement. At the same time, it creates the illusion that all these 
new things can replace all the old ones and requires changes in the entire education system. Nevertheless, we should decide (1) whether it is possible to replace live communication with the teacher by communicating via Skype; (2) whether it is possible to replace a classroom discussion with online communication; (3) the difference in the transfer of implicit knowledge, skills scientific, and thinking style learned when being near not virtually, but physically. In the renowned work Personal Knowledge, M. Polani wrote, " $<\ldots>$ in all cases, to master the art of cognition and action alone, it is not enough to learn rules and instructions or any of their individual pieces. One need to acquire a special skill for their effective coordination. The latter is due to the fact that it can also be verbally inexpressible to know the relations between individual concrete details that form a whole, even if all of them separately in the aggregate can be explicitly defined" (Polani, 1985). Any replacement of old things with the new ones, especially in education, should be carried out as carefully as possible, since the most serious negative consequences of any innovation in education may become noticeable only after decades; when correcting mistakes is possible, but not for everyone. Due to such mistakes, there can be entire generations that are called lost. The current introduction of information technology has both positive and negative sides. The solution does not require the rejection of the inevitable and particularly useful methods but requires well-thought-out methods and technologies for implementing the inevitable in the educational process.

\section{CONCLUSION}

Currently, to fulfil the potential of the modern education system, it is necessary to combine science, educational practices, and information technology. The introduction of information technology into the educational space involves the interaction of all subjects of the educational process (students, teachers, scientists, and experts in the field of information technology), which will allow students to form the ability to live in the digital world, master it, but not lose their humanity.

\section{ACKNOWLEDGMENT}

This research was supported by the Russian Presidential Grant for Leading Scientific Schools Return Migration and Migration Policy: Adaptive Strategies of Returnees and Receiving Population in Border Regions of Russia.

\section{REFERENCES}

Facione, P.A. (2016). Critical thinking: What it is and why it counts. Retrieved from https://www.insightassessment.com/article/critical-thinking-what-it-is-and-why-it-counts

Freier, P. (1972). Pedagogy of the oppressed. Trans. Myra Bergman Ramos. New York, NY: Herder. Retrieved from http://www.school-russia.prosv.ru/ebooks/best_pdf/paul_freire.pdf

Grechko, P.K., Kurmeleva, E.M., Grechko, P.K., Malkovskaya, I.A., Rudanovskaya, S.V., Pochta, Y.M., ... Bronzino, L.Y. (2009). Social: Origins, structural profiles, current challenges. Moscow, Russia: Russian Political Encyclopedia (ROSSPEN).

Heidegger, M. (1993). Time and being: Articles and speeches. Moscow, Russia: Republic.

Mikhailova, M. (2009). Aesthetics of silence. Saint Petersburg, Russia: Russian Christian Humanitarian Academy.

Motroshilova, N.V. (2010). Civilization and barbarism in the era of global crises. Moscow, Russia: Kanon+ Publ.

Podolsky, O. (2015). Literate people in Russia are more likely to be out of work: Scientists on functional illiteracy. Retrieved from https://theoryandpractice.ru/posts/10714-umeet-no-ne-mozhet

Polani, M. (1985). Personal knowledge. Moscow, Russia: Progress.

Pyatitgorsky, A.M. (2018). On education. Retrieved from http://in-nastavnik.ru/tekstyi/aleksandrpyatigorskiy-ob-obrazovanii.html

Shchedrovitsky, G.P. (1997). Philosophy. Science. Methodology. Moscow, Russia: Shk. cult. Politics. Toshchenko, Zh. T. (2008). A paradoxical person. Moscow, Russia: UNITY. 